\title{
Corollary discharge inhibition and audition in the stridulating cricket
}

Received: 8 December 2004 / Revised: 7 June 2005/ Accepted: 12 June 2005 / Published online: 25 October 2005

(C) Springer-Verlag 2005

\begin{abstract}
The romantic notion of crickets singing on a warm summer's evening is quickly dispelled when one comes ear to ear with a stridulating male. Remarkably, stridulating male crickets are able to hear sounds from the environment despite generating a $100 \mathrm{db}$ song (Heiligenberg 1969; Jones and Dambach 1973). This review summarises recent work examining how they achieve this feat of sensory processing. While the responsiveness of the crickets' peripheral auditory system (tympanic membrane, tympanic nerve, state of the acoustic spiracle) is maintained during sound production, central auditory neurons are inhibited by a feedforward corollary discharge signal precisely timed to coincide with the auditory neurons' maximum response to self-generated sound. In this way, the corollary discharge inhibition prevents desensitisation of the crickets' auditory pathway during sound production.
\end{abstract}

Keywords Corollary discharge Efference copy · Stridulation · Cricket · Auditory · Presynaptic inhibition

\section{Feedforward signals}

To gather sensory cues from the environment, animals have developed an array of highly sensitive sensory systems. These systems, however, not only respond to environmental sensory information, but also to stimuli generated as a by-product of the animal's own behaviour. In principle self-generated, or reafferent (von Holst and Mittelstaedt 1950), information could desensitise the animal's own sensory pathway and/or also be con-

J. F. A. Poulet

Laboratory of Sensory Processing, Brain Mind Institute, Faculty of Life Science, Ecole Polytechnique Federale de Lausanne, CH-1015 Lausanne, Switzerland

E-mail: james.poulet@epfl.ch

Tel.: + 41-21-6938352

Fax: +41-21-6938353 fused for external, or exafferent, sensory information of the same modality, which could elicit an inappropriate behavioural response. Thus, the discrimination between self-generated and external sensory stimuli is a fundamental problem in perception and a central question of sensory neuroscience.

Philosophers and scientists over the centuries have proposed that responses to self-generated stimuli are modulated by neural signals that feedforward from motor to sensory networks during behaviour (Grüsser 1986). In 1950 two papers furthered modern thinking about these concepts and termed the feedforward signals "corollary discharges" or "efference copies" (Sperry 1950; von Holst and Mittelstaedt 1950). More recently, these terms have been refined so that motor to sensory discharges indicate corollary discharge signals; whereas an efference copy is compared with the actual sensory feedback and represents an accurate negative image of the reafferent information (McCloskey 1981; Bell 1984). Neurophysiological evidence for these mechanisms requires recording neural activity during motor behaviour. Despite this technical difficulty, a growing body of evidence suggests that feedforward signals are widespread in the CNS and have been recorded from a number of sensory systems including visual (Zaretsky and Rowell 1979; Sommer and Wurtz 2002), vestibular (Roy and Cullen 2004), electrosensory (Bell 1989), mechanosensory (Murphey and Palka 1974; Delcomyn 1977; El Manira et al. 1996; Blakemore et al. 1998; Li et al. 2002) and proprioceptive systems (Sillar and Skorupski 1986; Gossard et al. 1991; Wolf and Burrows 1995).

\section{Auditory responsiveness during sound production}

During sound production, the auditory system of the caller must somehow discriminate self-generated from external sounds and prevent desensitisation. A modulation in the response of auditory neurons during sound production has been recorded in vertebrates-human: (Creutzfeldt et al. 1989; Numminen et al. 1999) monkey: 
(Müller-Preuss and Ploog 1981; Kirzinger and Jürgens 1991); bat: (Suga and Schlegel 1972; Suga and Shimozawa 1974; Schuller 1979; Metzner 1989; Metzner 1993); bird: (McCasland and Konishi 1981); grasshopper: (Hedwig 1986; Wolf and Helversen 1986; Hedwig 1990; Hedwig and Meyer 1994); and cicada: (Hennig et al. 1994). In the vertebrates the modulation is assumed to be the result of a centrally generated neural signal however, the exact properties and source of the inhibition have never been established. In the invertebrate systems studied so far, the modulation is the result of peripheral noise-making effects (Hedwig 1990; Hedwig and Meyer 1994; Hennig et al. 1994).

One animal that generates high-intensity sound pulses for communication and offers significant experimental advantages to analyse the problems above, is the stridulating cricket. Crickets posses well characterised and highly sensitive auditory systems to listen out for other crickets or predators. Although cricket auditory interneurons are desensitised by loud sounds (Pollack 1988; Samson and Pollack 2002; Poulet and Hedwig 2003a, b), behavioural experiments have shown that singing crickets are able to hear exafferent sounds (Heiligenberg 1969; Jones and Dambach 1973). To understand how crickets maintain auditory sensitivity during sound production, we examined the responsiveness of the crickets' peripheral and central auditory system to environmental and self-generated sound during pharmacologically elicited stridulation.

\section{Sound production in crickets}

Male crickets stridulate to attract mates and warn off rivals. During stridulation, or singing, crickets rub their forewings against each other to generate a series of sound pulses, or syllables, that are generated during the closing wing movements of the chirp (Fig. 1a). In Gryllus bimaculatus a chirp is composed of 3-5 syllables, which can reach up to $100 \mathrm{~dB}$ SPL re. $20 \mu \mathrm{Pa}$. Each chirp is separated by a $250 \mathrm{~ms}$ pause or chirp interval. Recently, pharmacological methods have been developed that elicit robust stridulation (Otto 1978; Wenzel and Hedwig 1999). Microinjections of acetylcholine, and other cholinergic agonists, into the cricket's anterior protocerebrum are thought to activate the stridulation command neurons that spur the thoracic central pattern generator into action (Hedwig 2000). Armed with this technique, it was possible to record from different stages of the crickets' auditory system during stridulation and analyse how the animals cope with the self-generated sound.

\section{Peripheral auditory responses during stridulation}

One strategy to cope with reafferent acoustic stimulation could be to modulate the sensitivity of the peripheral auditory system during sound production. Many
A
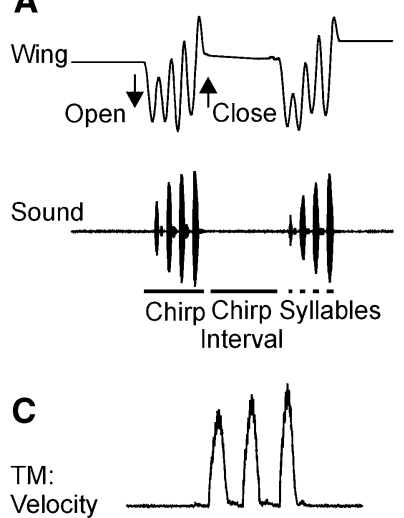

(RMS)

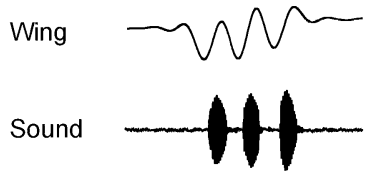

Wing: (a) $1.75 \mathrm{~mm}$, (c) $2 \mathrm{~mm}$, (d) $1 \mathrm{~mm}$

Abdomen: (b) $0.5 \mathrm{~mm}$

TM Velocity: (b) $1 \mathrm{~mm} \mathrm{~s}^{-1}$, (c) $5 \mathrm{~mm} \mathrm{~s}^{-1}$

TM Displacement: (b) $50 \mathrm{um}$

Tympanic Nerve: (d) $2 \mathrm{mV}$
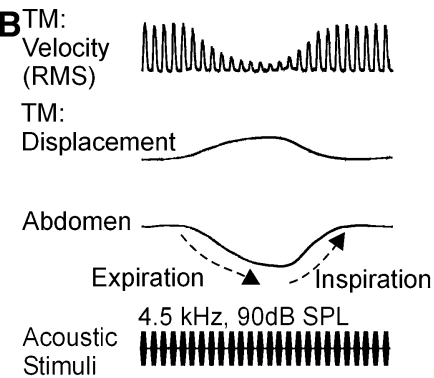

D
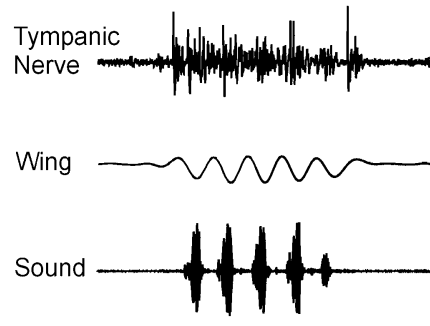

(a) $350 \mathrm{~ms}$, (b) $150 \mathrm{~ms}$ (c,d) $100 \mathrm{~ms}$

Fig. 1 Peripheral auditory responses during stridulation. a The sound pattern and associated wing movements during pharmacologically elicited calling song. b The tympanic membrane responded with a rapid oscillation to each sound pulse. However in one animal, and in animals with their acoustic spiracle waxed shut, there was a decrease in the amplitude of the oscillations in synchrony with ventilation. During sonorous stridulation, c the tympanic membrane oscillated vigorously and $\mathbf{d}$ the tympanic nerve responded with bursts of action potentials in response to each selfgenerated sound pulse. Wing, movement of the wing; Sound, sound recordings; $T M$ : velocity ( $R M S$ ), velocity of tympanic membrane oscillations given as the root mean square; TM: displacement, slow displacement of the tympanic membrane; Abdomen, movement of the abdomen; Acoustic stimuli, externally generated sound pulses; Tympanic nerve, extracellular recording of tympanic nerve. Used with permission from Poulet and Hedwig (2001, 2003b)

vertebrates and other invertebrates employ this mechanism (Suga and Jen 1975; Borg and Counter 1989; Narins 1992; Hennig et al. 1994). The first stage of sound processing in the cricket is at its tympanic membranes located on the tibiae of the forelegs (Larsen et al. 1989; Michelsen 1998). An H-shaped trachea, that has openings at the acoustic spiracles on either side of the thorax, acoustically couples the tympanic membranes. Therefore, sound is transmitted to the tympanic membranes from both the external and internal side (Hill and Boyan 1976; Larsen and Michelsen 1978; Michelsen 1994). Oscillations of the tympanic membranes are thought to deform auditory afferent dendrites and initiate action potentials (Kleindienst et al. 1983; Larsen et al. 1989). About 60 auditory afferent neurons project from the ear along prothoracic nerve 5 , the tympanic nerve, into the prothoracic ganglion (Ball et al. 1989). For a complete description of the activity of the peripheral auditory system during stridulation we measured the movements of the acoustic spiracle, the oscillations of the tympanic 
membranes and the activity of the whole tympanic nerve (Poulet and Hedwig 2001).

To examine the responsiveness of the tympanic membrane, we presented acoustic stimuli to stridulating crickets and measured the wing movements, sound produced and any oscillations or displacement with a laser vibrometer/interferometer. In a resting cricket, the tympanic membrane would oscillate with constant amplitude to $4.5 \mathrm{kHz}, 90 \mathrm{~dB}$ SPL sound pulses. Occasionally, during ventilation, the tympanic membrane was slowly displaced in synchrony with the abdominal pumping movements, as seen in other Orthoptera (Meyer and Hedwig 1995; Meyer and Elsner 1995). The displacements were accompanied by a decrease in the amplitude of the sound-induced oscillations (Fig. 1b). Waxing the spiracle shut could produce the same effect. Closing the acoustic spiracles could, therefore, control the amplitude of reafferent auditory input. However, during stridulation, the spiracles remained open. Therefore, the self-generated auditory signals had full access to both sides of the tympanic membranes. During stridulation the tympanic membrane oscillated in response to each self-generated syllable (Fig. 1c). Further analysis of the response of the tympanic membrane to computer generated sound pulses, showed that there was no change in its responsiveness during the chirp or chirp interval. Whole nerve recordings of the tympanic nerve in the foreleg of the cricket revealed a similar result: bursts of activity were recorded in response to the crickets own song (Fig. 1d), and the response to externally generated acoustic stimuli presented were not modulated throughout the song. Thus, in contrast to most other acoustically communicating animals, the cricket does not take advantage of a relatively simple mechanism to reduce the responsiveness of its peripheral auditory pathway during sound production. How then does the cricket's central auditory system copes with the mass of selfgenerated sensory input during stridulation?

\section{Central auditory responses during stridulation}

The auditory afferents terminate in the auditory neuropil in the anterior ventral prothoracic ganglion. Here they forward their information to the dendritic branches of auditory interneurons (Wohlers and Huber 1982). We went on to make intracellular recordings and stainings in the auditory neuropil from the axonal branches of the auditory afferents and from the dendrites of the auditory interneurons during stridulation. We recorded from three identified interneurons: (1) the omega neuron 1 $(\mathrm{ON} 1)$ is an $\Omega$-shaped, local auditory interneuron that is broadly tuned but is most sensitive to the carrier frequency of male calling song $(4.5 \mathrm{kHz})$ (Casaday and Hoy 1977; Popov et al. 1978; Wohlers and Huber 1978); (2) ascending neuron 1 (AN1) is tightly tuned to $4.5 \mathrm{kHz}$ sound stimuli but possesses an ascending axon that terminates in the brain (Boyan 1980; Wohlers and
Huber 1982; Stumpner et al. 1995). (3) Ascending neuron 2 (AN2) also ascends to the brain, it responds best to higher frequencies $(>10 \mathrm{kHz})$ and is inhibited, or only weakly excited, by $4.5 \mathrm{kHz}$ sound (Wohlers and Huber 1978, 1982; Boyan 1980; Nolen and Hoy 1987), which supports roles in courtship song recognition (Wohlers and Huber 1982) and bat detection during flight (Nolen and Hoy 1983).

As expected from the whole nerve recordings, single auditory afferent neurons responded with bursts of spikes in response to each syllable (Fig. 2a). Additionally prior to the start of some of the quieter chirps, the axonal arborisations of the afferents were depolarised (arrow, Fig. 2a). The interneurons ON1 (Fig. 2b) and AN1 (Fig. 2c) responded with bursts of spikes to the cricket's own song. However, as in the afferents, besides the excitation a second input was present in ON1 consisting of small hyperpolarising potentials (arrow, Fig. 2b). Unlike the other neurons, AN2 was inhibited during the chirps and rarely generated a spike (Fig. 2d).

To characterise the inhibitory inputs, we removed one of the wings and elicited silent stridulation. In the absence of any self-generated or external sounds in the afferent axon we recorded phasic groups of depolarising synaptic inputs termed primary afferent depolarisations or PADs (Fig. 3a). Each PAD started during the closing wing movements of the chirp when sound would normally have been generated. Recordings from ON1 during silent stridulation revealed clear groups of IPSPs in phase with each chirp (Fig. 3b). As with the PADs they started during the closing wing movements of each syllable and therefore must be expressed synchronous with ON1's spiking response during singing. Recordings from AN1 and AN2 showed small amplitude hyperpolarising potentials during the chirps (Fig. 3c, d). The large amplitude IPSPs recorded in AN2 during sonorous singing must therefore have been a response to reafferent input and correspond to the $4.5 \mathrm{kHz}$ inhibition.

To test what effect the PADs and IPSPs have on sound processing, we presented silently singing crickets with a continuous series of sound pulses. In this way, it was possible to evoke an auditory response in these neurons and examine any modification during the PAD or IPSP. Auditory afferents clearly responded with a train of spikes when presented with the sound pulses (Fig. 4a). The frequency of spiking in the afferent cells was consistent throughout the chirp and chirp intervals. However on closer inspection of the spike amplitude, those spikes coinciding with the PADs were reduced. The reduction in spike height is a good indication that the PADs have a presynaptic inhibitory function (Burrows and Matheson 1994; Clarac and Cattaert 1996). The PADs momentarily shunt the membrane resistance and cause a reduction in spike height that results in a smaller depolarisation of the axon terminal. Therefore, less neurotransmitter is released and the response in the postsynaptic cell is reduced. In a resting cricket and 


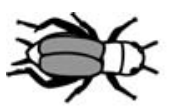

A

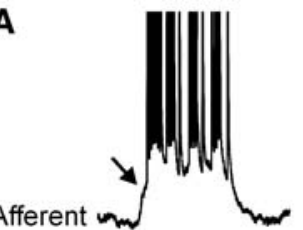

B

ON1

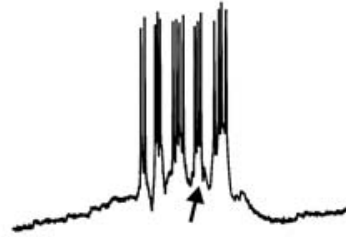

Wing

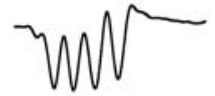

Wing

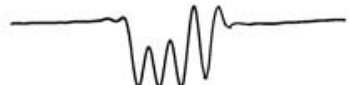

Sound

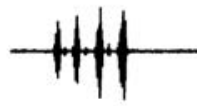

Sound

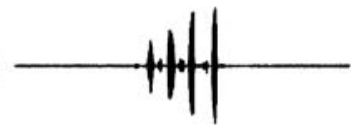

C

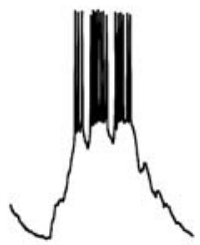

AN1

Wing

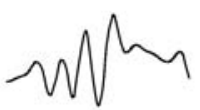

Sound Neuron: (a) $15 \mathrm{mV}$, (b) $20 \mathrm{mV}$,
(c) $30 \mathrm{mV}$, (d) $25 \mathrm{mV}$
Wing: $1 \mathrm{~mm}$

AN2

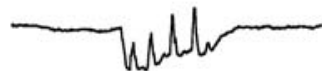

Wing

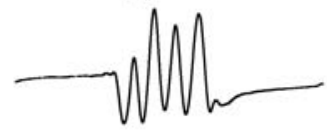

Sound

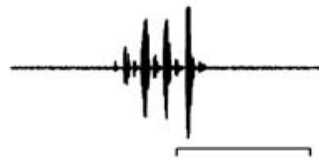

$(a, b, d) ,250 \mathrm{~ms}$

(c) $200 \mathrm{~ms}$

Fig. 2 Central auditory neural responses during sonorous, two winged, stridulation. a Auditory afferents responded with bursts of spikes during the chirp. Arrow indicates a depolarisation of the membrane prior to the first burst of spikes. b ON1 and c AN1 responded with bursts of spikes to syllables generated during the chirps. Arrow in b indicates small hyperpolarisations of ON1 superimposed on the excitatory response during the chirp. d AN2 was inhibited during the chirp, IPSPs were generated in response to each syllable. Afferent, intracellular recording of auditory afferent; $O N 1$, intracellular recording of omega neuron 1; $A N 1$, intracellular recording of ascending neuron 1; $A N 2$, intracellular recording of ascending neuron 2 . The cartoon crickets in this and the following figures represent a sonorously (two winged), silently (one winged) and fictively stridulating cricket. For further details, see Fig. 1. Used with permission from Poulet and Hedwig (2002, 2003a, 2003b)

during the chirp intervals, ON1, AN1 and AN2 all responded to the sound pulses with a continuous series of spikes to the exafferent stimuli, however they all failed to respond during the chirp (Fig. 4b, c, d). This inhibition of the auditory interneurons must therefore be a combination of the presynaptic inhibition acting at the afferent axon terminal and the direct postsynaptic inhibition mediated by the IPSPs.

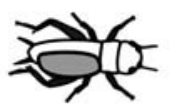

A

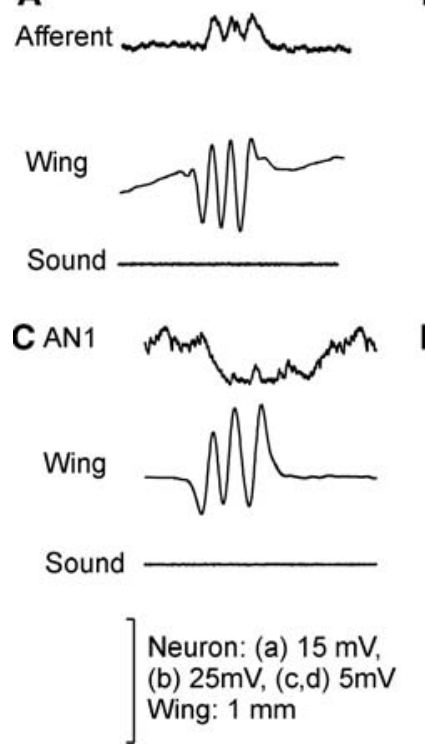

B

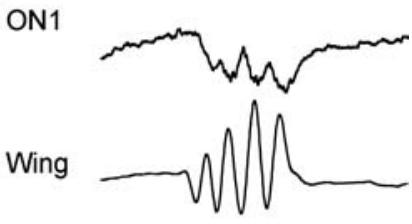

D AN2

Wing

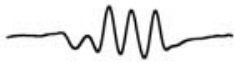

Sound

$250 \mathrm{~ms}$
Sound

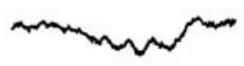

Fig. 3 Responses of central auditory neurons during silent, one winged, stridulation. a Phasic groups of PADs were recorded in auditory afferent neurons during silent chirps. b IPSPs were recorded in ON1 during silent chirps and closing wing movement. Low amplitude hyperpolarising potentials were recorded in $\mathbf{c} \mathrm{AN} 1$ and $\mathbf{d}$ AN2 during silent chirps. Both the PADs and IPSPs began just after the start of the wing closing and reached a maximum during the consecutive wing opening movement. For further details, see Figs. 1 and 2. Used with permission from Poulet and Hedwig (2002, 2003a, 2003b)

\section{Sensory feedback or feedforward signal?}

Alongside the reafferent input, we had identified an inhibitory input that occurred at the exact time of the maximum response to the crickets own song. The inhibitory inputs may have two sources: reafferent feedback from non-auditory sense organs activated during stridulation or from the network of neurons generating the stridulatory motor pattern and expressed as a feedforward neural signal. To distinguish between the two sources, we removed the sensory feedback and efferent output of the motor neurons by cutting the thoracic and abdominal lateral nerves and recorded the responses of the auditory neurons in fictively stridulating crickets (Poulet and Hedwig 2002, 2003a, b).

Recordings during fictive singing revealed the same pattern of inhibitory input in the auditory neurons as in the silently singing crickets. In the afferents, phasic groups of PADs were present during the chirps (Fig. 5a); IPSPs were recorded in ON1 (Fig. 5b) and small amplitude hyperpolarisations occurred in AN1 (Fig. 5c) and AN2 (Fig. 5d). The inhibitory inputs during the chirps had the same effect on sound processing as during silent singing on presenting a continuous series of sound 


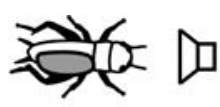

A

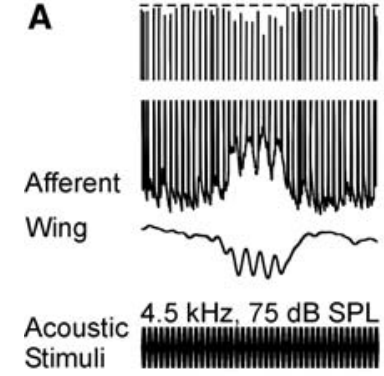

B

ON1

Wing
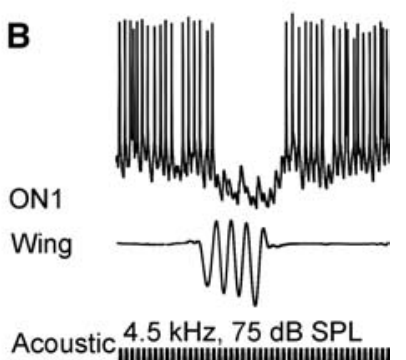

Stimuli

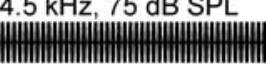

C

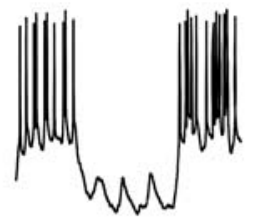

AN1

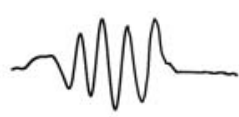

$4.5 \mathrm{kHz}, 75 \mathrm{~dB}$ SPL

Acoustic Stimuli
D

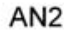

Wing

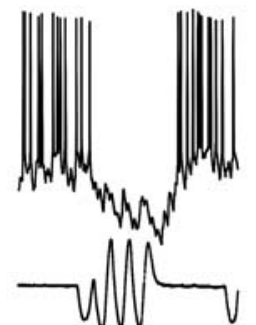

Acoustic $12.5 \mathrm{kHz}, 75 \mathrm{~dB}$ SPL Stimuli
Neuron: (a) $15 \mathrm{mV}$,
(b,c) $25 \mathrm{mV}$, (d) $30 \mathrm{mV}$
Wing: (a) $0.25 \mathrm{~mm}$,
(b,c) $1 \mathrm{~mm}$, (d) $1.5 \mathrm{~mm}$
Time: (a,b,d) $250 \mathrm{~ms}$,

(c) $150 \mathrm{~ms}$

Fig. 4 Responses of auditory neurons to acoustic stimuli presented during silent singing. a Auditory afferents showed no modulation in their firing rate to acoustic stimuli and responded with a constant train of spikes during the chirp and chirp intervals. However, those spikes coinciding with PADs during the chirp were reduced in amplitude (stippled line). b ON1, c AN1, and d AN2 all responded with spikes to the acoustic stimuli during the chirp intervals but their responses were completely inhibited during the chirps. For further details, see Figs. 1 and 2. Used with permission from Poulet and Hedwig (2002, 2003a, 2003b)

pulses. Just as in the silently singing crickets, the afferent neuron continued to spike throughout the chirp and chirp interval but the spike amplitude was reduced when it coincided with the PADs (Fig. 6a). The auditory interneurons responded to the sound during the chirp intervals but failed to respond during the chirp (Fig. 6b, $\mathrm{c}, \mathrm{d})$. This confirmed that the inhibitory inputs during the chirp were generated within the nervous system and were not the product of sensory feedback. As the inhibition did not completely cancel out responses to reafferent stimuli it appeared to be a corollary discharge signal rather than an efference copy.

\section{Biological significance of corollary discharge inhibition in the stridulating cricket}

To examine what long-term effect the inhibitory corollary discharge had on sensory processing, loud chirps were presented, which mimicked the cricket's own song,

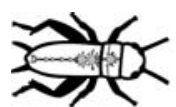

A

Afferent
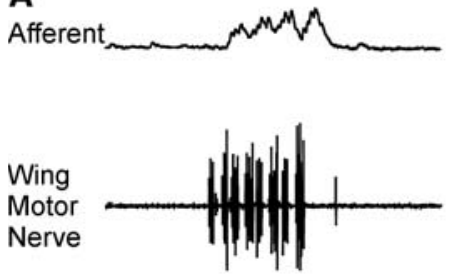

C AN1

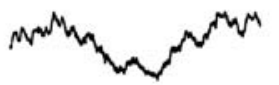

Wing

Motor

Nerve

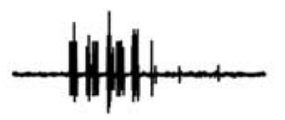

Neuron: $(a, b) 25 \mathrm{mV}$,

(c) $5 \mathrm{mv}$, (d) $10 \mathrm{mV}$

Wing Motor Nerve:

(a,c,d) $10 \mathrm{mV}$, (b) $12.5 \mathrm{mV}$
B

ON1
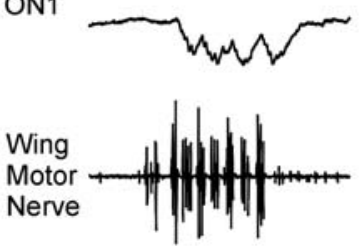

D

AN2

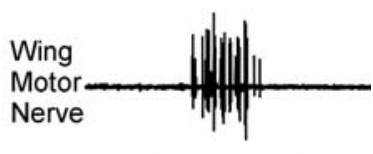

(a,b,c) $250 \mathrm{~ms}$

(d) $350 \mathrm{~ms}$
Fig. 5 Inhibitory inputs are present during fictive singing with all motor and sensory neurons cut. a PADs occur in auditory afferent neurons, b IPSPs occur in ON1 and low amplitude hyperpolarising potentials are present in $\mathbf{c}$ AN1 and d AN2 during the chirps. These inputs were therefore generated within the nervous system and the result of a corollary discharge signal. For further details, see Figs. 1 and 2. Used with permission from Poulet and Hedwig (2003a)

followed by quieter test pulses (Poulet and Hedwig 2002, 2003b). In a resting cricket, bursts of spikes in the auditory interneurons induce a long lasting hyperpolarising potential that can suppress responses to subsequent quieter sounds (Pollack 1988; Poulet and Hedwig 2003a, b). Responses to test pulses were decreased in ON1 if presented after a loud chirp (Fig. 7a, b). When the effect of the corollary discharge was mimicked, by injecting hyperpolarising current into ON1 during the loud chirp, the response the test stimuli returned (Fig. 7c). Thus, a reduction in response to loud reafferent sounds, mediated by the corollary discharge inhibition, will prevent desensitisation of the auditory pathway and help the cricket hear sounds from the environment.

\section{Conclusions and future work}

Sensory neural pathways are able to respond to exafferent stimuli, even during behaviours that generate intense reafferent stimulation. Neural recordings of sensory pathways made during motor behaviour, in vertebrates and invertebrates, point towards a similar solution to this feat: the central sensory pathway is modulated during the phase of behaviour that generates the reafferent stimuli. In more and more cases, both in vertebrates and invertebrates, centrally generated neural signals are responsible for the modulation. The logical 


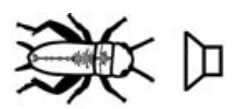

A

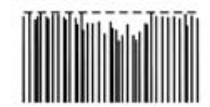

Afferent

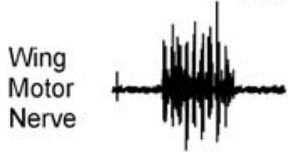

$4.5 \mathrm{kHz}, 75 \mathrm{~dB}$ SPL
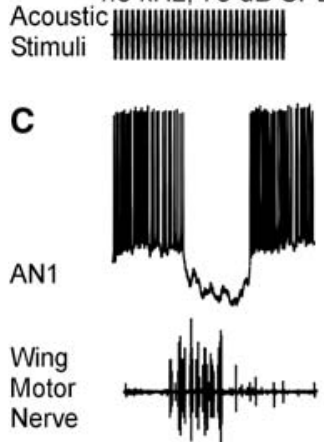

$4.5 \mathrm{kHz} .75 \mathrm{~dB}$ SPL

Acoustic Stimuli

$$
\begin{aligned}
& \text { Neuron: (a) } 15 \mathrm{mV} \\
& \text { (b,c,d) } 25 \mathrm{mV} \\
& \text { Wing Motor Nerve: } \\
& \text { (a,b,c) } 10 \mathrm{mV} \text {, (d) } 5 \mathrm{mV}
\end{aligned}
$$

B

ON1

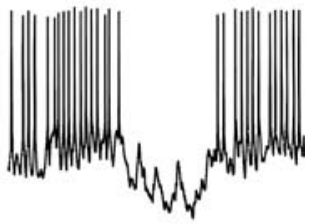

Wing

Motor

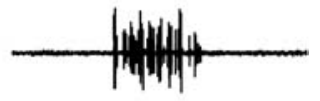

$4.5 \mathrm{kHz}, 75 \mathrm{~dB} \mathrm{SPL}$ Acoustic
Stimuli

D

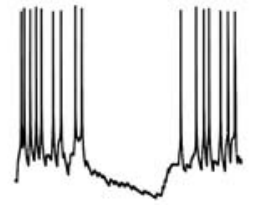

AN2

Wing

Nerve

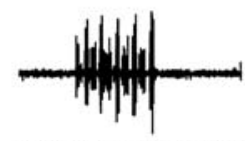

$12.5 \mathrm{kHz}, 75 \mathrm{~dB}$ SPL

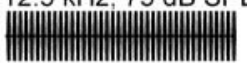

$250 \mathrm{~ms}$
Fig. 6 Effect of corollary discharge inhibition on sound processing in fictively singing crickets. a Auditory afferents responded to the acoustic stimuli with a constant train of spikes during the chirp and chirp intervals. Those spikes occuring at the same time as the PADs were reduced in amplitude. b ON1, c AN1, and d AN2 all responded with spikes to the test stimuli at rest and during the chirp intervals. But their response was inhibited during the chirps. For further details, see Figs. 1 and 2. Used with permission from Poulet and Hedwig (2002, 2003a, 2003b)

next step in the study of feedforward signals is to identify their source. Experiments are underway to characterise the physiological and anatomical basis of the corollary discharge signal in the stridulating cricket.

Acknowledgements I thank Dr Berthold Hedwig for his helpful comments on an earlier version of this manuscript. This work was supported by the BBSRC.

\section{References}

Ball EE, Oldfield BP, Rudolph KM (1989) Auditory organ structure, development and function. In: Huber F et al (eds) Cricket behaviour and neurobiology. Cornell University Press, Ithaca London, pp 391-422

Bell CC (1984) Effects of motor commands on sensory inflow, with examples from electric fish. In: Bolis L et al (eds) Comparative physiology of sensory systems. Cambridge University Press, Cambridge, pp 636-647
A

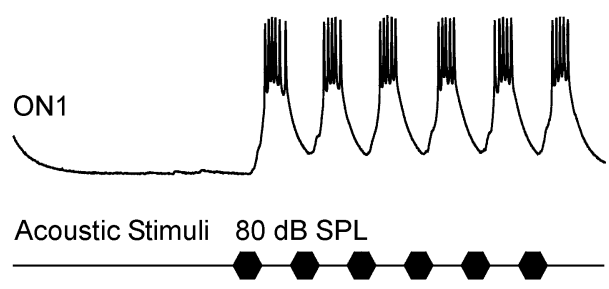

B

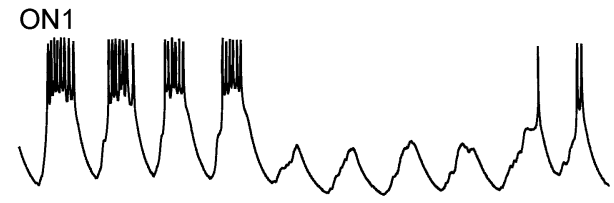

Acoustic Stimuli:

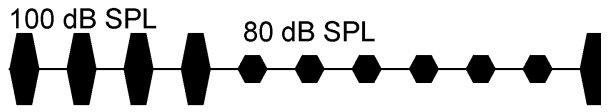

C
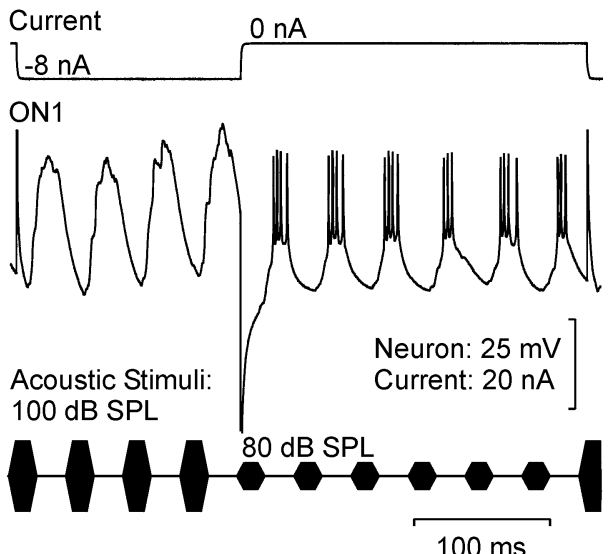

Fig. 7 Inhibition during loud chirps prevents subsequent desensitisation. a $\mathrm{ON} 1$ responds to a series of $4.5 \mathrm{kHz}, 80 \mathrm{~dB}$ test pulses with bursts of spikes. b If a $100 \mathrm{~dB}$ chirp is presented immediately prior to the quieter test stimuli, ON1's response is suppressed. c Hyperpolarising current injection into ON1 during the loud chirp prevented desensitisation to the test stimuli. For further details, see Figs. 1 and 2. Used with permission from Poulet and Hedwig (2003b)

Bell CC (1989) Sensory coding and corollary discharge effects in mormyrid electric fish. J Exp Biol 146:229-253

Blakemore S-J, Wolpert DW, Frith CD (1998) Central cancellation of self-produced tickle sensation. Nature Neurosci 1:635-640

Borg E, Counter S (1989) The middle-ear muscles. Sci Am 261:6268

Boyan GS (1980) Auditory neurones in the brain of the cricket Gryllus bimaculatus (De Geer). J Comp Physiol A 140:81-93

Burrows M, Matheson T (1994) A presynaptic gain control mechanism among sensory neurons of a locust leg proprioceptor. J Neurosci 14:272-282

Casaday B, Hoy RR (1977) Auditory interneurons in the cricket Teleogryllus oceanicus: physiological and anatomical properties. J Comp Physiol A 156:789-801

Clarac F, Cattaert D (1996) Invertebrate presynaptic inhibition and motor control. Exp Brain Res 112:163-180

Creutzfeldt O, Ojemann G, Lettich E (1989) Neuronal activity in the human lateral temporal lobe II. Responses to the subjects own voice. Exp Brain Res 77:476-489

Delcomyn F (1977) Corollary discharge to cockroach giant interneurons. Nature 269:160-162 
El Manira A, Tegner J, Grillner S (1996) Locomotor-related presynaptic modulation of primary afferents in the lamprey. Eur $\mathbf{J}$ Neurosci 9:696-705

Gossard J-P, Cabelguen J-M, Rossignol S (1991) An intracellular study of muscle primary afferents during fictive locomotion in the cat. J Neurophysiol 65:914-926

Grüsser O-J (1986) Interaction of efferenct and afferent signals in visual perception a history of ideas and experimental paradigms. Acta Psychologica 63:3-21

Hedwig B (1986) On the role in stridulation of plurisegmental interneurons of the acridid grasshopper Omocestus viridulus L. II. Anatomy and physiology of ascending and T-shaped interneurons. J Comp Physiol A 158:429-444

Hedwig B (1990) Modulation of auditory responsiveness in stridulating grasshoppers. J Comp Physiol A 167:847-856

Hedwig B (2000) Control of cricket stridulation by a command neuron: efficacy depends on the behavioural state. J Neurophysiol 83:712-722

Hedwig B, Meyer J (1994) Auditory information processing in stridulating grasshoppers: tympanic membrane vibrations and neurophysiology. J Comp Physiol A 174:121-131

Heiligenberg W (1969) The effect of stimulus chirps on a cricket's chirping. Z Vergl Physiol 65:70-97

Hennig RM, Weber T, Huber F, Kleindienst H-U, Moore TE, Popov AV (1994) Auditory threshold change in singing cicadas. J Exp Biol 187:45-55

Hill KG, Boyan GS (1976) Directional hearing in crickets. Nature 262:390-391

von Holst E, Mittelstaedt H (1950) Das Reafferenzprinzip: Wechselwirkungen zwischen Zentralnervensystem und Peripherie. Naturwissenschaften 37:464-476

Jones MDR, Dambach M (1973) Response to sound in crickets without tympanal organs (Gryllus campestris L.). J Comp Physiol A 87:89-98

Kirzinger A, Jürgens U (1991) Vocalization-correlated single-unit activity in the brain stem of the monkey. Exp Brain Res 84:545560

Kleindienst H-U, Wohlers DW, Larsen ON (1983) Tympanal membrane motion is necessary for hearing in crickets. J Exp Biol 151:397-400

Larsen ON, Michelsen A (1978) Biophysics of the ensiferan ear III. The cricket ear as a four input system. J Comp Physiol A 123:217-227

Larsen ON, Kleindienst K-U, Michelsen A (1989) Biophysical aspects of sound reception. In: Huber $F$ et al (eds) Cricket behaviour and neurobiology. Cornell University Press, Ithaca London, pp 364-390

Li W-C, Soffe SR, Roberts A (2002) Spinal inhibitory neurons that modulate cutaneous sensory pathways during locomotion in a simple vertebrate. J Neurosci 22:10924-10934

McCasland JS, Konishi M (1981) Interaction between auditory and motor activities in an avian song control nucleus. Proc Natl Acad Sci USA 78:7815-7819

McCloskey DI (1981) Corollary discharges: motor commands and perception. In: Brooks VB (ed) Handbook of physiology. The nervous system. Am Physiol Soc, Bethesda, pp 1415-1447

Metzner W (1989) A possible neuronal basis for Doppler-shift compensation in echolocating horseshoe bats. Nature 341:529-532

Metzner W (1993) An audio-vocal interface in echolocating horseshoe bats. J Neurosci 13:1899-1915

Meyer J, Elsner N (1995) How respiration affects auditory sensitivity in the grasshopper Chorthippus biguttulus (L.). J Comp Physiol A 176:563-573

Meyer J, Hedwig B (1995) The influence of tracheal pressure changes on the responses of the tympanal membrane and auditory receptors in the locust Locusta migratoria L. J Exp Biol 198:1327-1339

Michelsen A (1994) Directional hearing in crickets and other small animals. Fort der Zool 39:195-207

Michelsen A (1998) Biophysics of sound localization in insects. In: Hoy RR et al (eds) Comparative hearing: insects. Springer, Berlin Heidelberg New York, pp 18-62
Müller-Preuss P, Ploog D (1981) Inhibition of auditory cortical neurons during phonation. Brain Res 215:61-76

Murphey RK, Palka J (1974) Efferent control of cricket giant fibres. Nature 248:249-251

Narins PM (1992) Reduction of tympanic membrane displacement during vocalization of the arboreal tree frog, Eleutherodactylus coqui. J Acoust Soc Am 91:3551-3557

Nolen TG, Hoy RR (1983) Initiation of behaviour by single neurons: the role of behavioural context. Science 226:992-994

Nolen TG, Hoy RR (1987) Postsynaptic inhibition mediates highfrequency selectivity in the cricket Teleogryllus oceanicus: implications for flight pyhonotaxis behaviour. J Neurosci 7:2081-2096

Numminen J, Salmelin R, Hari R (1999) Subject's own speech reduces reactivity of the human auditory cortex. Neurosci Lett 265:119-122

Otto D (1978) Anderungen von Gesangsparametern bei der Grille (Gryllus campestris L.) nach Injektion von Pharmaka ins Gehirn. Verh Dt Zool Ges 245

Pollack GS (1988) Selective attention in an insect auditory neuron. J Neurosci 8:2635-2639

Popov AV, Markovich AM, Andjan AS (1978) Auditory interneurons in the prothoracic ganglion of the cricket, Gryllus bimaculatus deGeer I. The large segmental auditory neuron (LSAN). J Comp Physiol A 126:183-192

Poulet JFA, Hedwig B (2001) Tympanic membrane oscillations and auditory receptor activity in the stridulating cricket Gryllus bimaculatus. J Exp Biol 204:1281-1293

Poulet JFA, Hedwig B (2002) A corollary discharge maintains auditory sensitivity during sound production. Nature 418:872876

Poulet JFA, Hedwig B (2003a) Corollary discharge inhibition of ascending auditory information in the stridulating cricket. J Neurosci 23:4717-4725

Poulet JFA, Hedwig B (2003b) A corollary discharge mechanism modulates central auditory processing in singing crickets. J Neurophysiol 89:1528-1540

Roy JE, Cullen KE (2004) Dissociating self-generated from passively applied head motion: neural mechanisms in the vestibular nuclei. J Neurosci 24:2102-2111

Samson A-H, Pollack GS (2002) Encoding of sound localization cues by an identified auditory interneuron: effects of stimulus temporal pattern. J Neurophysiol 88:2322-2328

Schuller G (1979) Vocalization influences auditory processing in collicular neurons of the CF-FM-bat, Rhinolophus ferrumequinum. J Comp Physiol A 132:39-46

Sillar KT, Skorupski P (1986) Central input to primary afferent neurons in crayfish, Pacifastacus leniusculus, is correlated with rhythmic motor output of thoracic ganglia. J Neurophysiol 55:678-688

Sommer MA, Wurtz RH (2002) A pathway in primate brain for internal monitoring of movements. Science 296:1480-1482

Sperry RW (1950) Neural basis of the spontaneous optokinetic response produced by visual inversion. J Comp Physiol Psych 43:482-489

Stumpner A, Atkins G, Stout JF (1995) Processing of unilateral and bilateral auditory inputs by the ON1 and L1 interneurons of the cricket Acheta domesticus and comparison to other cricket species. J Comp Physiol A 177:379-388

Suga N, Jen P (1975) Peripheral control of acoustic signals in the auditory system of echolocating bats. J Exp Biol 62:277-311

Suga N, Schlegel P (1972) Neural attenuation of responses to emitted sounds in echolocating bats. Science 177:82-84

Suga N, Shimozawa T (1974) Site of neural attenuation of responses to self-vocalized sounds in echolocating bats. Science 183:1211-1213

Wenzel B, Hedwig B (1999) Neurochemical control of cricket stridulation revealed by pharmacological injections into the brain. J Exp Biol 202:2203-2216

Wohlers DW, Huber F (1978) Intracellular recording and staining of cricket auditory interneurons (Gryllus campestris L., Gryllus bimaculatus DeGeer). J Comp Physiol A 127:11-28 
Wohlers DW, Huber F (1982) Processing of sound signals by six types of neurons in the prothoracic ganglion of the cricket, Gryllus campestris L. J Comp Physiol A 146:161-173

Wolf H, Burrows M (1995) Proprioceptive sensory neurons of a locust leg receive rhythmic presynaptic inhibition during walking. J Neurosci 15:5623-5636
Wolf H, Helversen OV (1986) "Switching-off" of an auditory interneuron during stridulation in the acridid grasshopper Chorthippus biguttulus L. J Comp Physiol A 158:861-871

Zaretsky M, Rowell CHF (1979) Saccadic suppression by corollary discharge in the locust. Nature 280:583-585 